io be presented at the $M 1-13$ conterenct, september $\angle U-\angle 4,1$ yy

Victoria Conference Centre Victoria, B.C. Canada $\operatorname{con}+930926-.32$

BNL-49325

\title{
Partial Lifetime Test of an SSC Collider Dipole
}

P. Wanderer, M. Anerella, G. Ganetis, M. Garber, A.K. Ghosh, A. Greene, R. Gupta, A. Jain, S. Kahn, E. Kelly, G. Morgan, J. Muratore, A. Prodell, M. Rehak, E.P. Rohrer, W. Sampson, R. Shutt, R. Thomas, P. Thompson, E. Willen

RHIC Project, Brookhaven National Laboratory, Upton, NY 11973 U.S.A.'

and

A. Akhmetov, T. Bush, W. D. Capone II, R. Coombes, A. Devred, J. Dimarco, C. Goodzeit, J. Krzywinski, J. Kuzminski, W. Nah, T. Ogitsu, P. Radusewicz, R. Schermer, R. Stiening, J. C. Tompkins, M. Wake, J. Zbasnik, Y. Zhao, H. Zheng

Superconducting Super Collider Laboratory, Dallas, TX 75237 U.S.A.

Abstract- Over a period of ten months, a 15 m-long, $50 \mathrm{~mm}-$ aperture superconducting SSC Collider dipole was taken through a series of thermal and power cycles to check for changes in performance. One quench below operating current was experienced during this period. Small changes in the coil preload and cerrain harmonics were observed.

\section{INTRODUCTION}

The R\&D program for the Superconducting Super Collider dipoles at Brookhaven National Laboratory culminated with the construction of seven full-sized models. Five of these were built by staff from the Magnet Systems Division of the Westinghouse Electric Corporation as backups for the SSC Accelerator Systems String Test (ASST). The f construction and performance of these magnets bave been reported previously [1-5].

One magnet, DCA213, was kept on the test stand for ten mosths. During this time it was subjected to 2 total of 67 thermal cycles [6], about 2000 power cycles to the $6.6 \mathrm{kA}$ operating current [7], 40 conductor-limited, spontaneous quenches at $4.35 \mathrm{~K}$ or lower, and about 100 additional queaches from spot heaters, eddy currents, etc. The magnet was also operated successfully at reverse polarity, as a check on the suitability of the design for High Energy Booster magnets. The nominal SSC 25-year lifetime expectations for magnets are 50 thermal cycles, 100 quenches, and 20,000 power cycles [8].

A cross section of the magnet is given in Fig. 1. It is one of iwo ASST magnets that uses two layers of Kapton [9] for the turn-to-turn insulation of the cable [10], instead of the more traditional Kapton and epoxy-impregnated fiberglass.

\section{QUENCH PERFORMANCE}

The quench performance of the magnet is summarized in Fig. 2. For simplicity, only conductor-limited or training quenches are shown is this plot. The one training quench at $4.35 \mathrm{~K}$ occurred at the start of the third cold test period. The small variation in quench currents $4.35 \mathrm{~K}$ reflects changes in the helium temperature. Data from voltage taps indicated that the conductor-limited quenches occurred in the pole turn of the inner coil, as expected.

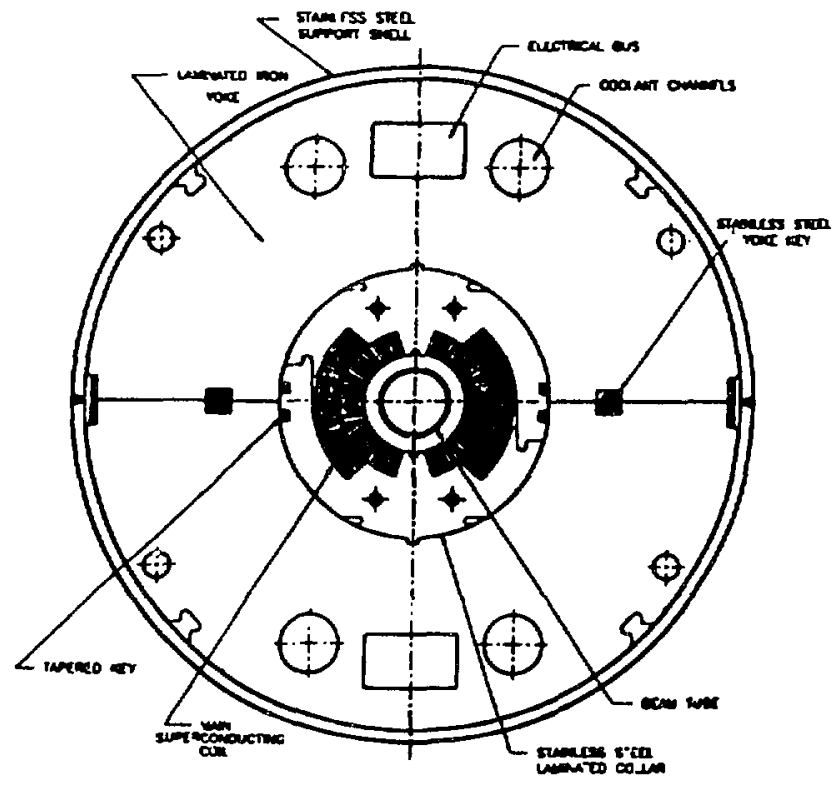

Figure 1. Cold mass cross section for dipole DCA213.

\section{AXIAL AND AZIMUTHAL FORCES}

Azimuthal prestress measured at the pole of the coil, at room temperature and at $4.35 \mathrm{~K}$ (for $\mathrm{I}=0$ ), is shown for the inner and outer coils in Fig. 3. The test periods at 4.35K are numbered. Within each test period, the initial one to three measurements were made before spontaneous quenching and the remainder were made after the quenching and various other types of tests. The predominant feature of the data is the (expected) prestress loss during cooldown. Another

'Manuscript received Seplember 20, 1993. Work performed under Contract No. DE-AC02-76CH00016 with the U.S. Departmemt of Energy. 


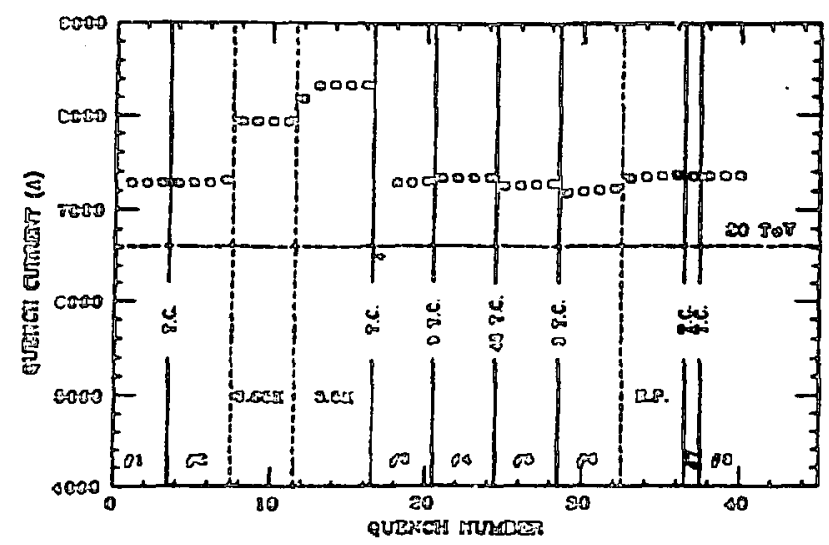

Figgure 2. Quencla history of the ruganet. Operation at Eowyer temperstures and at reverse folarity (RP) are moted separately. Therand cycles (TC) are indicaled by solid vertical lines; changes in umperature or polarity by dinshed lines.

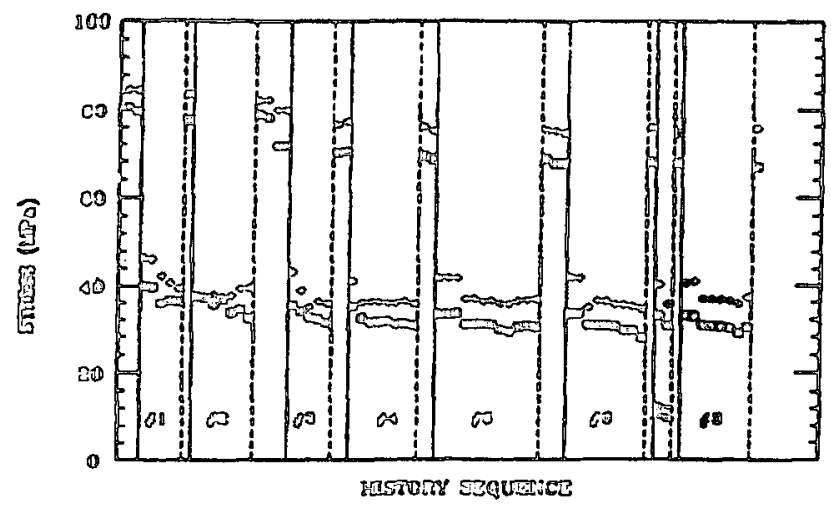

Fognonse 3. At one arial location, the overnge stress at the prole is sliown for the iraner( $(0)$ and outer( $\square$ ) coils duriag encts of the eight cest preriods at 4.35K and during the inaterveniog tione at room remperatoure.

fenture is the small decrease of prestress durring a given cold test pariod. These rwo features were basically the same for encli cest period. In addition, there is a gradual loss of prestress for any specific state of the magmet, with the rate of loss decrensing in the later test periods powever, the inner coil prestress for test pericd "s is slightly higher than for 47 ).

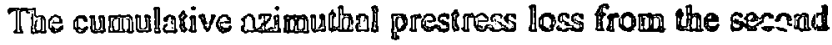
tharough the sijuth test periods car be seen in Fig. 4, where the prestress is plotted against lo squirare of the current, with $\mathbb{I}^{2}=44(\mathrm{kA})^{2}$ for $20 \mathrm{TeV}$. Possible cortuributors to the prestress loss are time at reom temparantre or themal cycling (90\% of the rower cycles occurred after the sixth cold test period).

The arial preload of the magnet ends is strown in similar pair of plots: Fig. 5 for the end force as a function of cold test period, Fig. 6 for the end force as a function of $\mathbb{1}^{2}$. The end forces are higher at room temperainure than at $4.35 \mathrm{~K}$. The forces in the lead and monlead ends for test periods four and later change gradually, but in opposite directions. The end forces during magnet excitation are essentially the same for the second and sistin test periods.

The observed changes in prestress ing the body of the magnet and prelosed is the ends are consistem with expectations based on thermal contraction coefficients and material properties. It elpould be voted that as $3.5 \mathrm{~K}$, where these magnets were operated far stove their nomml operating freld (Fig. 2), and no preatress remained af uhe pole, libule or mo training was required to reacio the conductor linait.

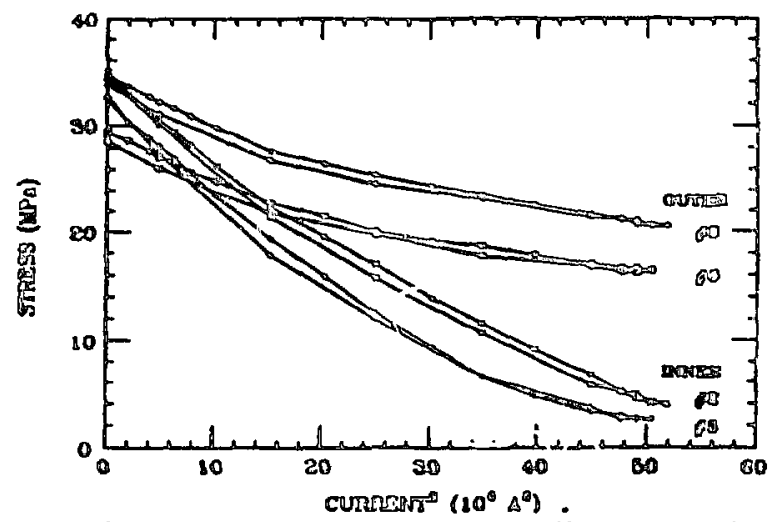

Figure 4. Ayerage inner and outer coil stress during magnet excitation, for the second and sixts $4.35 \mathrm{~K}$ test periods ( $44 \times 10^{6} \mathrm{~A}^{3}$ contesponds to $20 \mathrm{TeV}$ ).

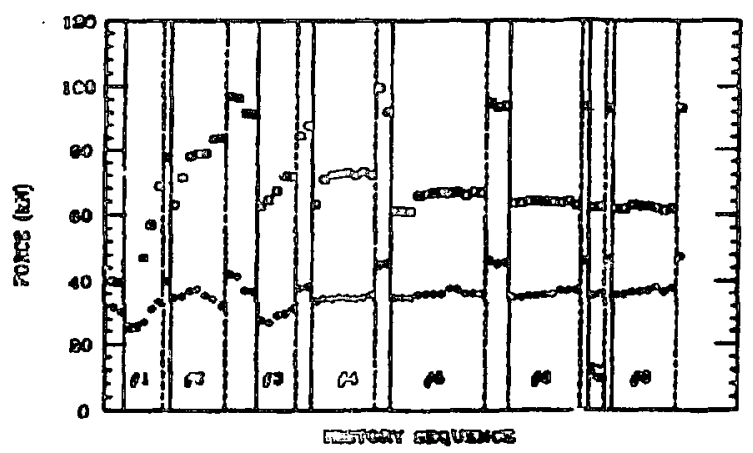

Figure 5. Total end force for the lead and nonlead ends with the same notation for the abscisss as Fig. 3.

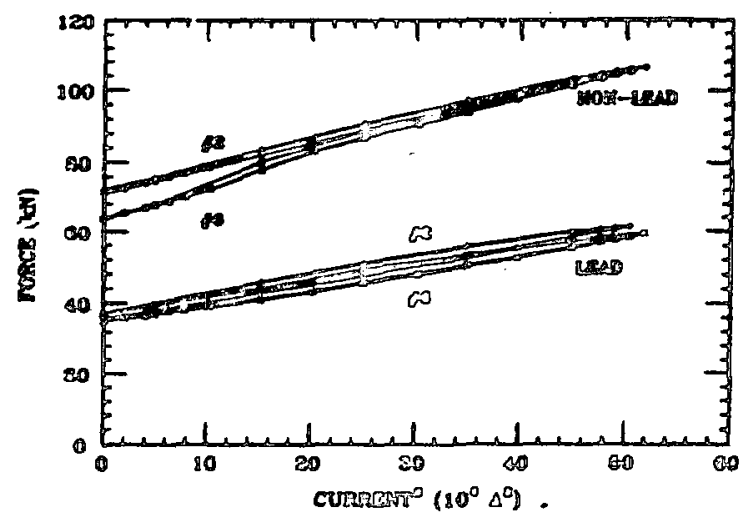

Figure 6. Total end force during raggnet excitation, for the second and sixth $4.35 \mathbb{K}$ test periods. 

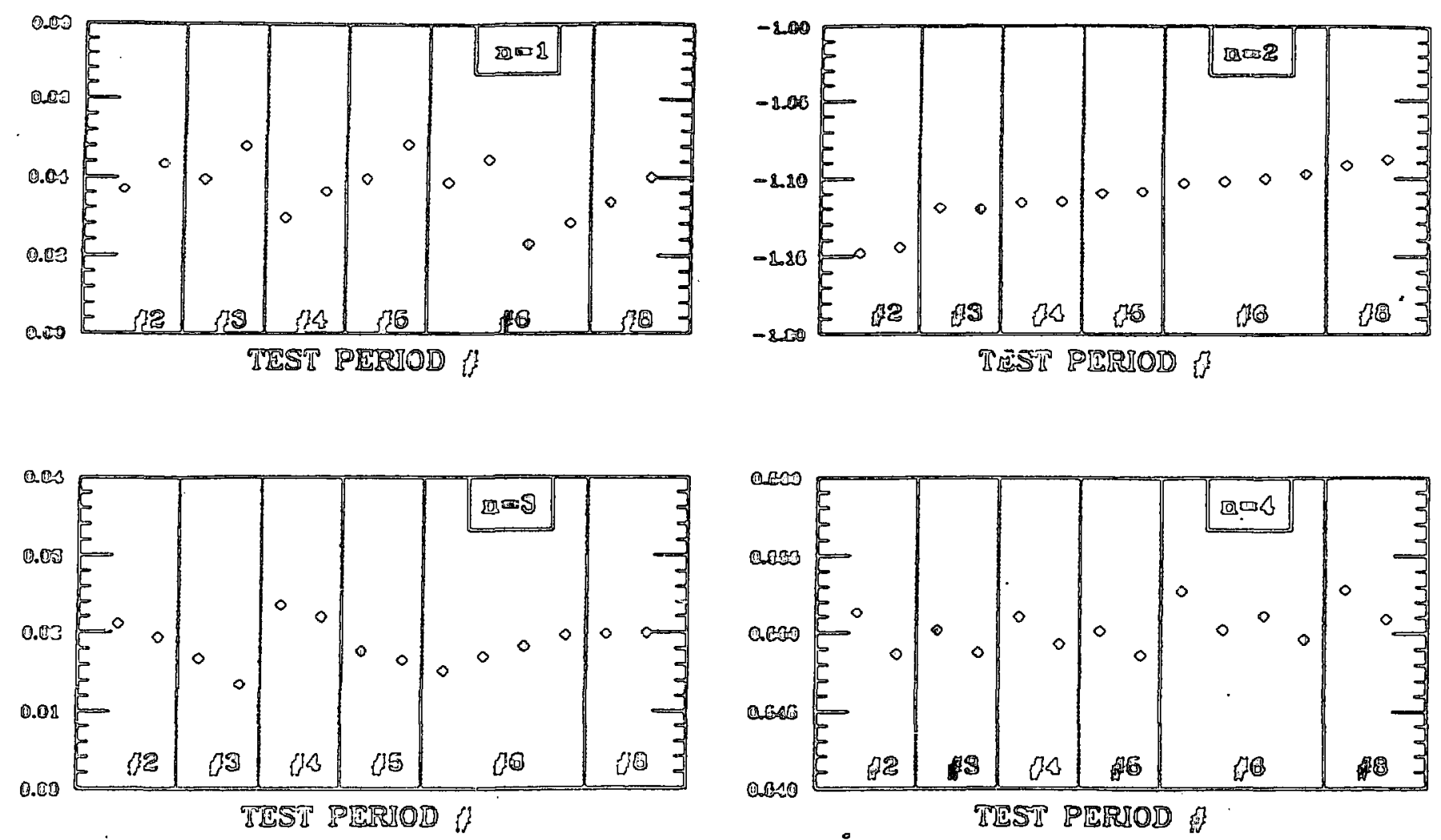

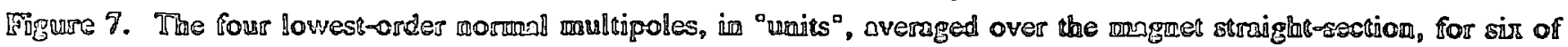

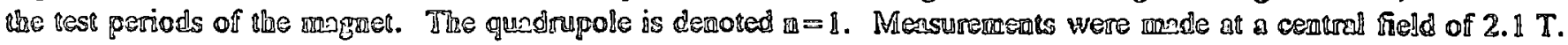
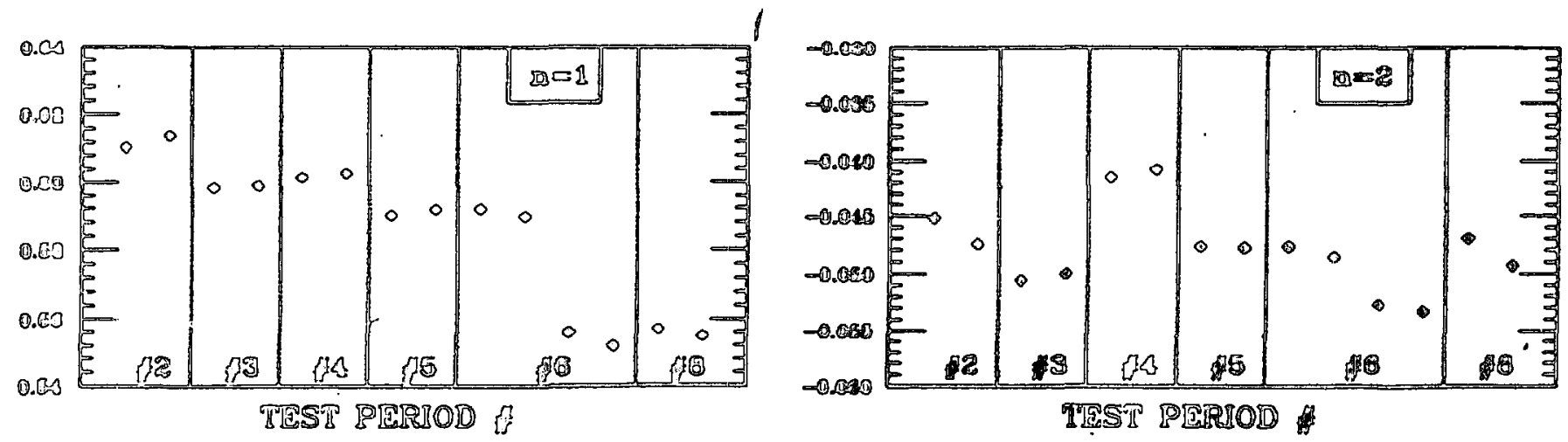

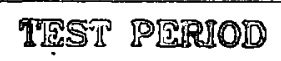
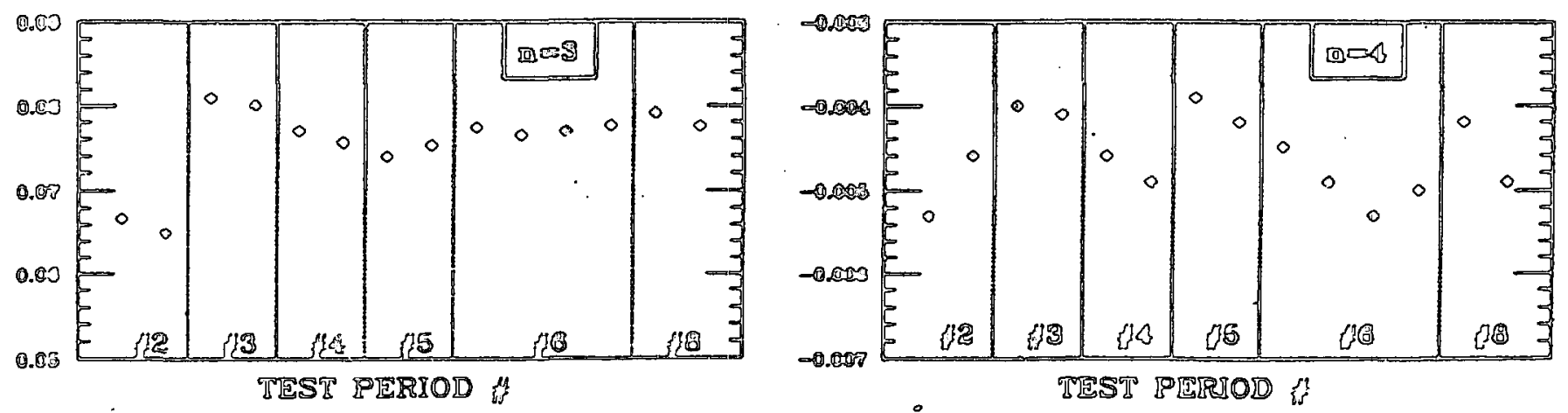

Figigre 8. Skew molitipoles, with the same notation as Fig. 7. 


\section{FIELD QUALITY}

For these magnets, the usual expression for the magnetic field is

$$
B_{y}+i B_{s}=B_{0} \sum_{z=0}^{\infty}\left(b_{n}+i a_{n}\right)(x+i y)^{n}
$$

where $x$ and $y$ are the horizontal and vertical coordinates and $B_{0}$ is the dipole field strength. It is convenient to refer to the coefficients evaluated at a radius of $10 \mathrm{~mm}$ and scaled by $10^{4} / \mathrm{B}_{0}$ as (dimensionless) "ivits." The a are the skew terms and the $b_{n}$ are the normal terms. The quadrupole coefficients have $a=1$. The data reported here are integrals summed over the magnet's straight section measured in $1 \mathrm{~m}$ increments with a system that includes a rotating coil and a gravity sensor [11]. The magnet current was $2 \mathrm{kA}(2.1 \mathrm{~T})$. The measurements have been corrected for feeddown effects and are all made with the same rotating coil. The uncertainty in the scale is estimated to be about 5\%.

Multipole measurements for six $4.35 \mathrm{~K}$ test periods are shown in Figs. 7 and 8 for the normal and skew coefficients respectively. In each test period the harmonics were measured at least twice in consecutive runs, so these pairs of runs give an indication of the short-term measuring uncertainty. In test period six, the harmonics were measured before and after (but not during) the period of negative polarity operation.

No systematic change is seen in five of the harmonics. There is a long-term drift of the normal sextupole $b_{2}$, together 1 with a step between cold periods two and three. A plot of the arial variation of $b_{2}$ for the initial and final runs shows the change to be uniform over the length of the magnet. The long-term drift is of the sign to be expected if the turns of the coils are gradually being compressed toward the midplane. (However, this is not directly caused by power cycles. The change in $b$, between periods six and eight is typical of the progression, while $90 \%$ of the power cycles occurred during this time.) Between the measurements of test periods two and three, the magnet was operated at $3.5 \mathrm{~K}$ and was at room temperature for two months. The total change in $b_{2}$, about 0.06 units, is small compared to the systematic tolerance at high freld, 0.8 units. Interestingly, an increase in $a_{3}$ of slightly more than 0.01 units occurred at the same time as the step ing $b_{2}$.

The skew quadrupole $a_{1}$ shows both a long-term decrease of abour 0.02 units and a step decrease during period six of 0.04 units [12]. Along the magnet axis, the decrease in $a_{1}$ during period six occurs entirely in the magnet half toward the lead end. The principal event occurring during period six was operation of the magnet at reverse polarity. The magnetic forces don't change when the polarity is reversed. However, the iron bysteresis loop is quite different for unipolar and bipolar operation. If borne out by further tests, the change in $a_{1}$ would be important if it were systematic (tolerance 0.04 units) but negligible if it were random (tolerance 1.25 units).

Within the measurement error (about $0.2 \mathrm{mrad}$ ), the axial variation of the dipole sagle did not change during the test.

\section{REFERENCES AND FOOTNOTES}

(1) C. Goodzeit a al., "Cold Mass Mochanical Design, Quench, and Mechanical Tear Results for Full Length $50 \mathrm{~mm}$ Aperture SSC Model Dipoles built a BNL," Proc. XVth Intn'l Conf. High Energy Acceleraton, Hamburg. Germany, 1992, published in Int. J. Mod. Phys. A. (Proc. Suppl.) 2A, p. 584 (1993).

[2] P. Wanderer at al., "Magnetic Design and Field Quality Measurements for Full Length $50 \mathrm{~mm}$ Aperture SSC Model Dipoles Built at BNL," ibid., p. 641.

[3] W. Nah a al., "Quench Characteristics of 5-cm-Aperture, 15-m-Long SSC Dipole Magna Prototypes," IEEE Trans. Applied Superconductivity, Vol. 3, No. 1, Merch 1993. p. 658 .

[4] T. Ogitsu \& al., "Mechanical Performance of 5-cmAperture, 15-m-Long SSC Dipole Magnet Prototypes," ibid., p.686.

[5] Y. Zhao at al., "Current Dependence of Harmonic Field Coefficients of 5-cm-Aperture, 15-m-Long SSC Dipole Magnet Prototypes," ibid., p674.

[6] Nine of the thermal cyclea were between room temperature and $4.35 \mathrm{~K}, 58$ between room temperature and $70 \mathrm{~K}$. Thermal cycles to $70 \mathrm{~K}$ were run as a background activity to other magnet testing. Since $97 \%$ of the thermal contraction of iron and strinless stcel takes place by $70 \mathrm{~K}$, the cycles to $70 \mathrm{~K}$ have essentially the same effect $2 \mathrm{~s}$ cycles to $4.35 \mathrm{~K}$.

[7] Most of the power cycles were at $100 \mathrm{~N} / \mathrm{sec}$ and $3.85 \mathrm{~K}$, as compared to the Collider ramp rate of 4 Nece at $4.35 \mathrm{~K}$.

[8] "Site-Specific Conceptual Design Executive Summary," SSCL-SR-1055 (July 1990) p. 31.

[9] Kapton is a registered trademark of the Dupont Corporation.

[10] M. Anerella, A.K. Ghosh, J. Schmalzle, E. Willen, "Improved Cable Insulation for Superconducting Magnets," 1993 Particle Acceleralor Conference, Werhington D.C., May 17-20, 1993 (to be publishod).

[11] R. Thomas et al., "Performance of Fieid Measuring Probes for SSC Magnets," Proc. Fith Annual International Industrial Symposium on the Superconducting Super Collider, San Francisco, CA, May 6-8, 1993 (10 be published).

[12] In principle, errors in correcting for the feeddown from $b_{2}$ to $a_{1}$ could be a spurious source of change, but given the small size of $b_{2}$ in the magnet and the lack of change in the centering distance for these runs, the amount of $a_{1}$ which could be due to centering errors in negligible. 